\title{
Trend in survival after out-of-hospital cardiac arrest and its relationship with bystander cardiopulmonary resuscitation: a six-year prospective observational study in Beijing
}

\author{
Yuling Chen ${ }^{1 \dagger}$, Peng Yue ${ }^{1 \dagger}$, Ying Wu ${ }^{1 *}$, Jia Li ${ }^{1}$, Yanni Lei ${ }^{2}$, Ding Gao ${ }^{2}$, Jiang $\mathrm{Liu}^{2}$ and Pengda Han ${ }^{2}$
}

\begin{abstract}
Background: Out-of-hospital cardiac arrest (OHCA), a global health problem with a survival rate ranging from 2 to $22 \%$ across different countries, has been a leading cause of premature death for decades. The aim of this study was to evaluate the trends of survival after OHCA over time and its relationship with bystander cardiopulmonary resuscitation (CPR), initial shockable rhythm, return of spontaneous circulation (ROSC), and survived event.

Methods: In this prospective observational study, data of OHCA patients were collected following the "Utstein style" by the Beijing, China, Emergency Medical Service (EMS) from January 2011 (data from February to June in 2011 was not collected) to October 2016. Patients who had a cardiac arrest and for whom an ambulance was dispatched were included in this study. All cases were followed up to determine hospital discharge or death. The trend of OHCA survival was analyzed using the Chi-square test. The relationship among bystander CPR, initial shockable rhythm, ROSC, survived event, and OHCA survival rate was analyzed using multivariate path analyses with maximum standard likelihood estimation.

Results: A total of 25,421 cases were transferred by the Beijing EMS; among them, 5042 (19.8\%) were OHCA (median age: 78 years, interquartile range: $63-85,60.1 \%$ male), and 484 (9.6\%) received bystander CPR. The survival rate was $0.6 \%$, which did not improve from 2012 to $2015(P=0.569)$. Overall, bystander CPR was indirectly associated with an $8.0 \%(\beta=0.080,95 \%$ confidence interval $[C I]=0.064-0.095, P=0.002)$ increase in survival rate. The indirect effect of bystander CPR on survival rate through survived event was $6.6 \%(\beta=0.066,95 \% C l=0.051-0.081, P=0.002)$, which accounted for $82.5 \%$ (0.066 of 0.080 ) of the total indirect effect. With every 1 increase in survived event, the possibility of survival rate will directly increase by $53.5 \%(\beta=0.535,95 \% C l=0.512-0.554, P=0.003)$.
\end{abstract}

Conclusions: The survival rate after OHCA was low in Beijing which has not improved between 2012 and 2015. The effect of bystander CPR on survival rate was mainly mediated by survived event.

Trial registration

\footnotetext{
*Correspondence: helenywu@vip.163.com

${ }^{\dagger}$ Yuling Chen and Peng Yue contributed equally to the publication of this manuscript.

${ }^{1}$ School of Nursing, Capital Medical University, No. 10, You An Men Wai Xi

Tou Tiao, Fengtai District, Beijing 100069, China

Full list of author information is available at the end of the article
}

(c) The Author(s) 2021. Open Access This article is licensed under a Creative Commons Attribution 4.0 International License, which permits use, sharing, adaptation, distribution and reproduction in any medium or format, as long as you give appropriate credit to the original author(s) and the source, provide a link to the Creative Commons licence, and indicate if changes were made. The images or other third party material in this article are included in the article's Creative Commons licence, unless indicated otherwise in a credit line to the material. If material is not included in the article's Creative Commons licence and your intended use is not permitted by statutory regulation or exceeds the permitted use, you will need to obtain permission directly from the copyright holder. To view a copy of this licence, visit http://creativecommons.org/licenses/by/4.0/. The Creative Commons Public Domain Dedication waiver (http://creativeco mmons.org/publicdomain/zero/1.0/) applies to the data made available in this article, unless otherwise stated in a credit line to the data. 
Chinese Clinical Trial Registry: ChiCTR-TRC-12002149 (2 May, 2012, retrospectively registered). http://www.chictr.org. $\mathrm{cn} /$ showproj.aspx?proj=7400

Keywords: Cardiac epidemiology, Critical care, Public health, Cardiac arrest, Cardiopulmonary resuscitation, Survival

\section{Background}

Out-of-hospital cardiac arrest (OHCA), a global health problem with a survival rate ranging from 2 to $22 \%$ across different countries [1], has been a leading cause of premature death from cardiovascular disease (CVD) for decades [2]. It is estimated that OHCA accounts for $50 \%$ of all CVD deaths in the world and for over 550,000 deaths in China annually [2]. The mortality rate from OHCA is projected to increase due to the rapid ageing of the population around the world [3] and in China [4].

Bystander cardiopulmonary resuscitation (CPR) has been proposed as the early link in the 'Chain of Survival' and is one of the most important modifiable factors in increasing the OHCA survival rates [5-7]. In the last decades, efforts have been made to increase the bystander CPR rate in most countries, especially in developed countries [8]. Along with the increased bystander CPR rate, OHCA survival rates have been increasing in some developed counties [9-11]. For instance, the bystander $\mathrm{CPR}$ rates and OHCA survival rates increased as follows: from $39.4 \%$ in $2006-2009$ to $48.9 \%$ in $2014-2016$, and from 10.4 to $14.9 \%$ in the same period of time in Canada [9]; from $28.2 \%$ in 2005 to $36.3 \%$ in 2012, and from 5.7 to $9.8 \%$ in the same period of time in the United States [11]; from $65.8 \%$ in 2006 to $81.2 \%$ in 2012, and from 16.2 to $19.7 \%$ in the same period of time in the Netherlands [10].

However, the survival rates in Asia-Pacific countries in which bystander CPR systems are also well developed, such as in Japan and Australia, are still unsatisfactory [12, 13]. In Japan, bystander CPR increased over time from $36.6 \%$ in 2005 to $48.4 \%$ in 2009 , but the neurologically favorable survival rate only increased from $1.6 \%$ in 2005 to $2.8 \%$ in 2009 [12]. Similar results were observed in Victoria, Australia, where bystander CPR increased from $55 \%$ in 2011 to $60 \%$ in 2016, but no change was observed in survival rates in adults after OHCA in the same period of time [13].

Evidence has shown that the OHCA survival rate is closely associated with many pre-hospital modifiable factors besides bystander CPR $[6,9,14,15]$, including initial shockable rhythm, early defibrillation, return of spontaneous circulation (ROSC), and survived event (defined as ROSC sustained until the arrival at the emergency department and transfer of care to medical staff at the receiving hospital) $[6,9,14,15]$. Most studies focused on exploring the relationship between prehospital factors and the survival rate after OHCA using multivariate logistic regression analysis [16-18]. The pathway among bystander CPR, other pre-hospital factors (such as initial shockable rhythm, ROSC, survived event), and survival rate after OHCA, however, remains unclear [19]. Previous prospective cohort studies found that bystander CPR may prolong the duration of the shockable rhythm [19], which might contribute to the increased ROSC rate [20] and survived event rate [21]. A cross-sectional observational study using the nationwide OHCA registry database in Korea [22] found that compared with no bystander CPR, bystander CPR was associated with increased rates of defibrillation and ROSC, therefore, increasing survival rate.

Data from Canada, the United States, and the Netherlands, where OHCA survival rates have increased over time, have shown that most of the pre-hospital modifiable factors such as bystander CPR, initial shockable rhythm, ROSC, and survived event improved over time [9-11]. In Japan and Australia, although the rates of bystander CPR, initial shockable rhythm, and ROSC were increased, the rates of survival after OHCA and survived event were not improved over time [12, 13, 23]. Therefore, we hypothesized that the effect of bystander CPR

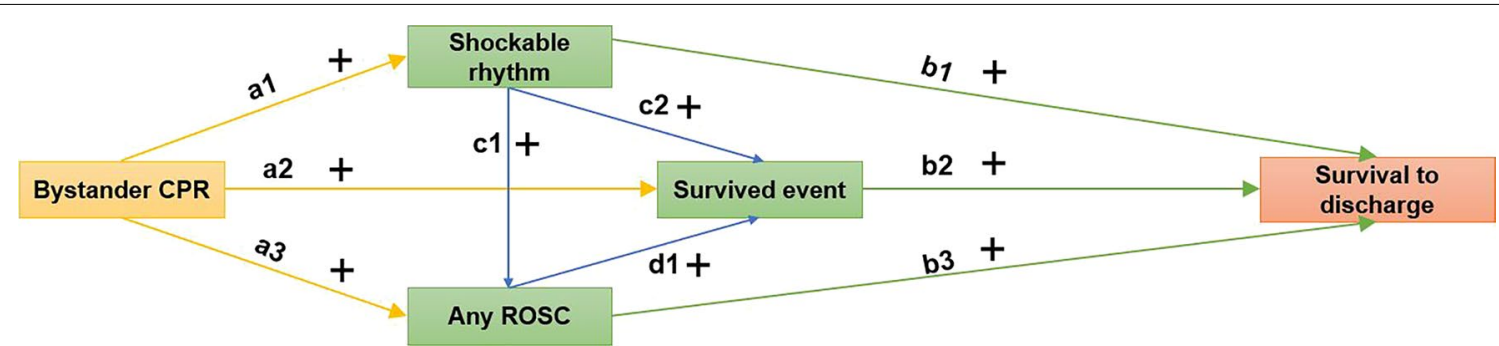

Fig. 1 Proposed model of bystander cardiopulmonary resuscitation on survival of out-of-hospital cardiac arrest. ROSC, return of spontaneous circulation; CPR, cardiopulmonary resuscitation 
on increasing OHCA survival rate was mainly mediated by survived event and partially mediated by shockable rhythm and ROSC (Fig. 1). The aims of this prospective observational study were to examine the pathway among bystander CPR, initial shockable rhythm, ROSC, survived event, and OHCA survival rate, and evaluated the temporal trend of survival after OHCA over time in Beijing, China.

\section{Methods}

\section{Study design, setting and population}

In this prospective observational study, data of OHCA patients were collected following the "Utstein style" [15] by the Beijing, China, Emergency Medical Service (EMS) from January 2011 (data from February to June in 2011 was not collected) to October 2016. Patients who had a cardiac arrest and for whom an ambulance was dispatched were included in this study. Cardiac arrest was defined as the absence of circulation signs, regardless of whether the assessment was made by the EMS or by a bystander [15]. All cases were followed up to determine hospital discharge or death. This study was approved by the Institutional Review Board of the Capital Medical University (No. 2010SY26). Informed consent from participants was waived by the Institutional Review Board of the Capital Medical University. The study was carried out in accordance with the Strengthening the Reporting of Observational studies in Epidemiology (STROBE) guidelines [24].

\section{System description}

Beijing has a population of 21.73 million people, with approximately 18.80 million residing in urban areas across $16,410 \mathrm{~km}^{2}$ [25]. There are two separate EMS systems in Beijing: one is Beijing 120, a public medical rescue organization of the Beijing Municipal Health Commission; the other is Beijing 999, which is subordinate to the Beijing Red Cross. Although people call 120 or 999 randomly, the reported number of dispatches for patients who called 120 was three times higher than dispatches for patients who called 999. Only cases of cardiac arrest that occurred in the Beijing urban area and that were served by Beijing 120 were included in this study (Fig. S1, Additional file 1).

Rescue ambulances equipped with electrocardiograph machines and defibrillators were dispatched to transfer OHCA patients to hospitals in this study. All ambulances were staffed with one physician, one nurse, and one driver, and they received special training in performing CPR and advanced cardiac life support (ACLS). The EMS physicians and nurses performed CPR and ACLS when indicated (except hypothermia therapy) either on site or on the ambulance following the resuscitation guidelines
[26-28]. The patients were assessed and treated by physicians in the emergency department after transfer to the receiving hospitals prior to hospital admission. It should be noted that automated external defibrillators (AEDs) were not yet available in public areas during the study period except in the Capital International Airport Terminal Three.

\section{Data collection procedures}

Patients' characteristics were collected prospectively on the ambulances by EMS physicians who were trained to use an Utstein registration sheet for documenting OHCA events. For each OHCA case, the EMS physician completed a registration sheet including the following: (1) general demographic information, such as age and gender; (2) first witness and initial management measures, such as the location of the cardiac arrest, whether the patients received bystander CPR, and whether the witness was trained in CPR; (3) assessment and treatment by the EMS crew, such as patients' mental status, vital signs, type of initial rhythm when the ambulance arrived, type of rhythm when the patient arrived at the emergency department, defibrillation, tracheal intubation, medication administration, probable cause of the cardiac arrest (cardiac, respiratory, traumatic, drowning, asphyxia, suicide, drug overdose, others), cardiovascular history, achieved ROSC, and survived event; and (4) timing-related information, such as the date and time of the cardiac arrest, time of the emergency call, and time the ambulance arrived. In addition, information was collected by reviewing the medical records regarding whether the patient died in the hospital, survived to admission, and survived to discharge.

\section{Operational definition}

Any ROSC was defined "according to a clinical assessment that comprised a palpable pulse or a blood pressure at any point during the resuscitation attempt" [15]. A survived event was defined as "ROSC sustained until the arrival at the emergency department and transfer of care to medical staff at the receiving hospital" [15]. Survival to admission was defined as "patients having ROSC after the treatment in the emergency department and being hospitalized" [15]. Survival to discharge was defined as patients having ROSC at the point of hospital discharge. A resuscitation attempted by EMS personnel was defined as a resuscitation when EMS personnel perform chest compressions or attempt defibrillation [15].

\section{Data analysis}

First, we analyzed the characteristics and survival rates among five groups of patients: (1) all OHCA patients, (2) those that EMS attempted to resuscitate, (3) those 
that EMS did not attempt to resuscitate, (4) those patients who were transported to a hospital with ROSC (that is, those who survived the event), and (5) those patients who were transported to a hospital with ongoing bystander CPR.

Second, we compared the differences in characteristics between patients who survived to discharge and those who did not survive to discharge, among all OHCA patients after excluding 28 patients who were lost-to-follow-up at hospital discharge. Student $t$ or Mann-Whitney $U$ tests were used for continuous data. Chi-square or Fisher's exact tests were carried out for categorical data. We performed the same analyses among those that EMS attempted to resuscitate, those who survived the event, and those who were transported to a hospital with ongoing bystander CPR.

Third, to evaluate the trends of survival rates and pre-hospital factors over time, a trend chi-square test (linear-by-linear) was conducted for dichotomous data; linear regression was used in case of normally distributed continuous variables. The Jonckheere-Terpstra test was used for non-normally distributed continuous variables. Given that OHCA cases from February to June in 2011 and from November to December in 2016 were not collected, we analyzed only those trends from 2012 to 2015. Analyses were conducted using IBM SPSS Statistics software (version 24, IBM Corp., Armonk, New York, USA).

Finally, to analyze the relationship among bystander CPR, initial shockable rhythm, any ROSC, survived event, and OHCA survival rate, multivariate path analyses with maximum standard likelihood estimation were conducted using IBM SPSS Amos 24.0. The multivariate path analyses were performed among all OHCA patients (model 1) and among those that EMS attempted to resuscitate (model 2). Three steps were carried out to test the mediation effect as follows: (1) The joint significance of the mediation path was used to indicate that full mediation had occurred. (2) The product of the path was calculated to assess the amount of mediation effect. (3) A bootstrapping method with bias-corrected confidence estimates was used to assess the significance of the indirect path.

The acceptable model fitting values for these measures were defined as follows: (1) nonsignificant chi-square value; (2) comparative fit index $>0.90$; (3) goodness of fit index $>0.90$; (4) Tucker Lewis index $>0.90$; (5) root mean square error of approximation $<0.08$; and (6) standardized root mean squared residual $<0.08$ [29]. Effect sizes were measured using the standardized estimates and were evaluated at the following levels: $0.1=$ small; $0.3=$ medium; $0.5=$ large. The model was modified until its indices fit well.
A series of sensitivity analyses were conducted to enhance the rigor of the study findings. First, we performed a path model (model 3) assuming that survival to admission was a mediator between survived event and survival to discharge. Second, we conducted a path model (model 4) using survival to admission as a dependent variable. Third, we performed three path models (models 5, 6, and 7) assuming that all patients who were lost-to-follow-up were dead.

\section{Results}

Figure 2 displays the flowchart of sample recruitment and the number of patients in different stages of resuscitation. A total of 25,421 case were transferred by Beijing EMS during the study period; among them, 5042 patients were confirmed as OHCA and were included in the final analysis. Characteristics of OHCA in Beijing during the study period are shown in Table 1 . Among 5,042 patients confirmed as OHCA, 3,032 (60.1\%) were male, with a median age of 78 (interquartile range [IQR]: 63-85) years, and $88.3 \%$ (4,452 cases) were of cardiac etiology. Of all the enrolled OHCA cases, 484 (9.6\%) received bystander CPR before the arrival of EMS personnel; 2,278 (45.2\%) were recorded as resuscitation attempted by EMS personnel; 2,764 (54.8\%) patients did not receive resuscitation because the victims were obviously dead.

\section{Survival rate}

As shown in Table 1, overall, the rates of patients who survived to discharge, survived to admission, and survived the event were $0.6 \%$ (31 of 5014, excluding 28 patients lost-to-follow-up at hospital discharge), 1.5\% (78 of 5042), and 2.4\% (121 of 5042), respectively. Among patients that EMS attempted to resuscitate, the rates of patients who survived to discharge, survived to admission, and survived the event were $1.4 \%, 3.4 \%$, and $5.2 \%$, respectively. Among patients that EMS did not attempt to resuscitate, only 3 patients survived event, and no case survived to admission or discharge. Among patients who were transported to hospital with ongoing bystander CPR, the rates of patients who survived to discharge, survived to admission, and survived the event were $3.1 \%$, $6.1 \%$, and 9.4\%, respectively. As shown in Fig. 2, among patients who survived to admission, 39.7\% (31 of 78) survived to discharge, $24.4 \%$ (19 of 78 ) died after being hospitalized, and $35.9 \%$ ( 28 of 78 ) were lost-to-follow-up.

\section{Trends in survival rates after OHCA from 2012 to 2015}

Table 2 displays the trends in survival rates after OHCA, demographic characteristics of enrolled patients (age and gender), bystander CPR, bystander CPR training, and response time from 2012 to 2015. No changes were observed in the rates of survival to discharge 


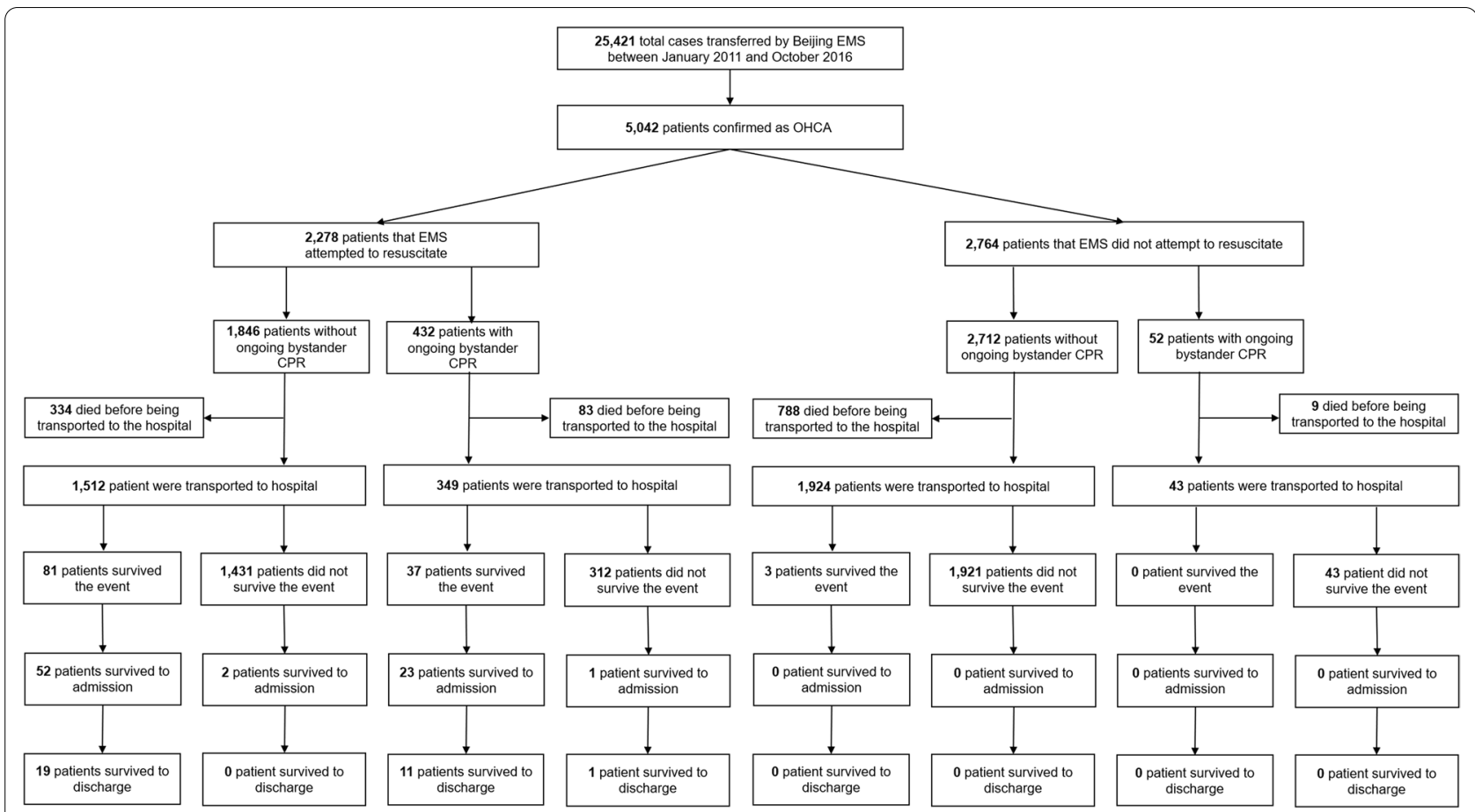

Fig. 2 Flow chat of the study. OHCA, Out-of-Hospital Cardiac Arrest; EMS, Emergency Medical Services; ROSC, return of spontaneous circulation

$\left(P_{\text {for trend }}=0.569\right.$, excluding 28 patients lost-to-followup at hospital discharge), survival to admission ( $P_{\text {for }}$ trend $=0.732)$, or survived event $\left(P_{\text {for trend }}=0.659\right)$ from 2012 to 2015 for all OHCA patients. For patients that EMS attempted to resuscitate, the rates were also stable for survival to discharge $\left(P_{\text {for trend }}=0.846\right.$, excluding 28 patients who lost to follow-up at hospital discharge), survival to admission $\left(P_{\text {for trend }}=0.709\right)$, or survived event $\left(P_{\text {for trend }}=0.749\right)$ from 2012 to 2015 . A small increase in the median age was found, from 77 (IQR: 62-84) years in 2012 to 79 (IQR: 64-85) years in $2015\left(P_{\text {for trend }}=0.004\right)$, but no change was found for gender $\left(P_{\text {for trend }}=0.815\right)$. Although no improvement was observed in bystander CPR training from 2012 to 2015 ( $\left.P_{\text {for trend }}=0.133\right)$, the rate of bystander CPR increased from $7.1 \%$ to $11.2 \%\left(P_{\text {for }}\right.$ trend $=0.005)$ during this period, with a relative increase rate of $57.7 \%$. A small increase in the response time was detected from 15 (IQR: 11-19) minutes to 16 (IQR: $12-20)$ minutes during this period $\left(P_{\text {for trend }}<0.001\right)$.

\section{Bystander CPR and bystander CPR training}

As shown in Table 1, among all enrolled OHCA cases, 484 (9.6\%) received bystander CPR (271 of 484 of these bystanders had CPR training). The differences in characteristics between patients who survived to discharge and those who did not survive to discharge were summarized in Table 3 and Table S1 (Additional file 1). As shown in Table 3, although significant differences in the survival rates were observed among victims who received or did not receive bystander CPR, the rates of survival to discharge were both very low: only $2.5 \%$ (12 of 481$)$ and $0.4 \%$ (19 of 4533$)$ among all OHCA patients $(P<0.001)$; and $2.8 \%$ (12 of 429$)$ and 1.0\% (19 of 1821) among those that EMS attempted to resuscitate $(P<0.001)$. As shown in Table S1 (Additional file 1), among patients who survived the event, no difference was found in the rate of survival after OHCA for victims who received or did not receive bystander CPR $(P=0.904)$. Bystanders with previous $C P R$ training did not change the rate of survival to discharge whether they performed CPR or not (Figure S2, Additional file 1). There was no dispatcher-assisted bystander CPR or bystander AED use during the study period.

\section{Initial rhythm}

Among the enrolled OHCA cases, only 162 (3.2\%) had initial shockable rhythm (including ventricular fibrillation or pulseless ventricular tachycardia). Cases with initial non-shockable rhythm (which accounted for 93.0\% [4689]) were pulseless, with no electrical rhythm and were in asystole. There were 191 cases (3.8\%) with other initial rhythm noted as myocardial infarction, atrial fibrillation, or ventricular escape; however, cardiac arrest occurred during the transfer to the hospital among those cases. Among the 191 cases, only 1 (0.5\%) victim survived to discharge. As shown in Table 3, among 
Table 1 Characteristics of out-of-hospital cardiac arrest in Beijing

\begin{tabular}{|c|c|c|c|c|c|}
\hline Characteristics & $\begin{array}{l}\text { Overall } \\
(n=5042)\end{array}$ & $\begin{array}{l}\text { EMS attempted to } \\
\text { resuscitate } \\
(\mathrm{N}=2278)\end{array}$ & $\begin{array}{l}\text { EMS did not attempt } \\
\text { to resuscitate } \\
(\mathrm{N}=2764)\end{array}$ & $\begin{array}{l}\text { Transported to hospital } \\
\text { with ROSC }(\mathrm{N}=121)\end{array}$ & $\begin{array}{l}\text { Transported to hospital with } \\
\text { ongoing bystander CPR } \\
(\mathrm{N}=392)\end{array}$ \\
\hline Age, median (IQR) & $78(63-85)$ & $70(57-80)$ & $82(73-87)$ & $69(55-79)$ & $68(57-80)$ \\
\hline \multicolumn{6}{|l|}{ Gender } \\
\hline Male & $3032(60.1)$ & $1574(69.1)$ & $1458(52.7)$ & $67(55.4)$ & $282(71.9)$ \\
\hline Female & 2010 (39.9) & $704(30.9)$ & $1306(47.3)$ & $54(44.6)$ & $110(28.1)$ \\
\hline \multicolumn{6}{|l|}{ Arrest location } \\
\hline At home & $4319(85.7)$ & $1727(75.8)$ & $2592(93.8)$ & $83(68.6)$ & $299(76.3)$ \\
\hline At public place & $723(14.3)$ & $551(24.2)$ & $172(6.2)$ & $38(31.4)$ & $93(23.7)$ \\
\hline \multicolumn{6}{|l|}{ Witnessed status } \\
\hline Non-witnessed & $2837(56.3)$ & $854(37.5)$ & $1983(71.8)$ & $26(21.5)$ & $122(31.1)$ \\
\hline Witnessed & $2203(43.7)$ & $1424(62.5)$ & $779(28.2)$ & $95(78.5)$ & $270(68.9)$ \\
\hline \multicolumn{6}{|l|}{ Bystander CPR } \\
\hline Yes & $484(9.6)$ & $432(19.0)$ & $52(1.9)$ & $37(30.6)$ & $392(100.0)$ \\
\hline No & $4558(90.4)$ & $1846(81.0)$ & $2712(98.1)$ & $84(69.4)$ & 0 \\
\hline \multicolumn{6}{|c|}{ Bystanders trained in CPR } \\
\hline Yes & $469(9.3)$ & $319(14.0)$ & $150(5.4)$ & $37(30.6)$ & $223(56.9)$ \\
\hline No & $4573(90.7)$ & $1959(86.0)$ & $2614(94.6)$ & $84(69.4)$ & $169(43.1)$ \\
\hline \multicolumn{6}{|c|}{ First monitored shockable rhythm } \\
\hline Yes & $162(3.2)$ & $149(6.5)$ & $13(0.5)$ & $26(21.5)$ & $50(12.8)$ \\
\hline No & $4880(96.8)$ & $2129(93.5)$ & $2751(99.5)$ & $95(78.5)$ & $342(87.2)$ \\
\hline \multicolumn{6}{|l|}{ Etiology } \\
\hline Cardiac & $4452(88.3)$ & $2045(89.8)$ & $2407(87.1)$ & $104(86.0)$ & $358(91.3)$ \\
\hline Non-cardiac & $590(11.7)$ & $233(10.2)$ & $357(12.9)$ & $17(14.0)$ & $34(8.7)$ \\
\hline \multicolumn{6}{|l|}{ Previous CVD } \\
\hline Yes & $3249(64.8)$ & $1436(63.0)$ & $1929(66.1)$ & $58(47.9)$ & $261(66.6)$ \\
\hline No & $1765(35.2)$ & $842(37.0)$ & $936(33.9)$ & $63(52.1)$ & $131(33.4)$ \\
\hline $\begin{array}{l}\text { Response time (min), } \\
\text { median (IQR) }\end{array}$ & $15(12-20)$ & $15(11-19)$ & $16(12-20)$ & $14(11-18)$ & $15(12-19)$ \\
\hline Defibrillated by EMS & $359(7.1)$ & $359(15.8)$ & 0 & $42(35.6)$ & $82(20.9)$ \\
\hline \multicolumn{6}{|l|}{ Any ROSC } \\
\hline Yes & $95(1.9)$ & $86(3.8)$ & $9(0.3)$ & $19(15.0)$ & $25(6.4)$ \\
\hline No & $4947(98.1)$ & $2191(96.2)$ & $2754(99.7)$ & $102(85.0)$ & 367 (93.6) \\
\hline \multicolumn{6}{|l|}{ Survived event } \\
\hline Yes & $121(2.4)$ & $118(5.2)$ & $3(0.1)$ & $121(100.0)$ & $37(9.4)$ \\
\hline No & 4921 (97.6) & $2160(94.8)$ & 2761 (99.9) & 0 & $355(90.6)$ \\
\hline \multicolumn{6}{|l|}{ Survived to admission } \\
\hline Yes & $78(1.5)$ & $78(3.4)$ & 0 & $75(62.0)$ & $24(6.1)$ \\
\hline No & $4964(98.5)$ & 2200 (96.6) & $2764(100.0)$ & $46(38.0)$ & $368(93.9)$ \\
\hline \multicolumn{6}{|l|}{ Survived to discharge } \\
\hline Yes & $31(0.6)$ & $31(1.4)$ & 0 & $30(24.8)$ & $12(3.1)$ \\
\hline No & $4983(98.8)$ & 2219 (97.4) & $2764(100.0)$ & $65(53.7)$ & $377(96.2)$ \\
\hline Lost to follow-up & $28(0.6)$ & $28(1.2)$ & 0 & $26(21.5)$ & $3(0.8)$ \\
\hline
\end{tabular}

Data are shown as frequency (percentage) or median (interquartile range). CPR, cardiopulmonary resuscitation; CVD, cardiovascular disease; IQR, interquartile range; ROSC, return of spontaneous circulation

all OHCA patients, the rate of survival to discharge was $7.1 \%$ (11 of 156) in those OHCA victims with initial shockable rhythm, and $0.4 \%$ (20 of 4858) in those with initial non-shockable rhythm (including other initial rhythm; $P<0.001)$. Among those that EMS attempted to resuscitate, the rate of survival to discharge was $7.7 \%$ (11 of 143) in those OHCA victims with initial shockable rhythm, and $0.9 \%(20$ of 2,107$)$ in those with initial 
Table 2 Trends in the survival after OHCA, pre-hospital factors from 2012 to 2015

\begin{tabular}{|c|c|c|c|c|c|}
\hline Variables & 2012 & 2013 & 2014 & 2015 & $P_{\text {for trend }}$ \\
\hline OHCA patients, $n$ & 920 & 1021 & 625 & 1174 & \\
\hline Age (years, median, IQR) & $77(62-84)$ & $77(63-84)$ & $77(62-85)$ & $79(64-85)$ & 0.004 \\
\hline Male $(n, \%)$ & $547(59.5)$ & $707(62.5)$ & $406(58.4)$ & $791(60.2)$ & 0.815 \\
\hline Response time (minutes, median, IQR, & $15(11-19)$ & $15(12-20)$ & $16(12-20)$ & $16(12-20)$ & $<0.001$ \\
\hline Bystander CPR (n, \%) & $65(7.1)$ & $114(10.1)$ & $59(8.5)$ & $147(11.2)$ & 0.005 \\
\hline Bystanders trained in CPR $(n, \%)$ & $79(8.6)$ & $111(9.8)$ & $70(10.1)$ & $139(10.6)$ & 0.133 \\
\hline Survived event (EMS attempted resuscitation, n, \%) & $20(4.4)$ & $28(5.0)$ & $16(5.2)$ & $25(4.8)$ & 0.749 \\
\hline Survived event (all OHCA patients, n, \%) & $20(2.2)$ & $28(2.5)$ & $17(2.4)$ & $26(2.0)$ & 0.659 \\
\hline Survival to admission (EMS attempted resuscitation, n, \%) & $12(2.6)$ & $21(3.7)$ & $10(3.3)$ & $17(3.3)$ & 0.709 \\
\hline Survival to admission (all OHCA patients, n, \%) & $12(1.3)$ & $21(1.9)$ & $11(1.6)$ & $17(1.3)$ & 0.732 \\
\hline Survived to discharge (EMS attempted resuscitation, n, \%) & $5(1.1)$ & $8(1.4)$ & $5(1.6)$ & $5(1.0)$ & 0.846 \\
\hline Survived to discharge (all OHCA patients, n, \%) & $5(0.5)$ & $8(0.7)$ & $6(0.9)$ & $5(0.4)$ & 0.569 \\
\hline
\end{tabular}

CPR, cardiopulmonary resuscitation; EMS, Emergency Medical Services; OHCA, Out-of-Hospital Cardiac Arrest; IQR, interquartile range

non-shockable rhythm (including other initial rhythm; $P<0.001$; Table 3).

\section{Any return of spontaneous circulation}

Any ROSC was achieved in 95 OHCA cases (1.9\%). Among patients who had any ROSC, $18.9 \%$ (18 of 95) survived the event, $14.7 \%$ (14 of 95 ) survived to admission, and $6.3 \%$ (6 of 95 ) survived to discharge. As shown in Table 3, among all OHCA patients, the rate of survival to discharge was $6.7 \%$ (6 of 90) in those OHCA victims with any ROSC and $0.5 \%$ (25 of 4923) in those without $(P<0.001)$. Among those that EMS attempted to resuscitate, the rate of survival to discharge was $7.4 \%$ (6 of 81 ) in those OHCA victims with any ROSC and 1.2\% (25 of $2,169)$ in those without ROSC $(P<0.001)$.

\section{The relationship and pathways among bystander CPR, other prehospital factors, and the survival rate}

The result of the multivariate path analysis among all OHCA patients is displayed in Fig. 3 (model 1) and Table 4 . The tested model had a proper fit. In this model, we excluded 28 patients lost-to-follow-up. As shown in Table 4, no direct relationship was found in bystander $\mathrm{CPR}$ and OHCA survival. The indirect effect of bystander CPR on OHCA survival was significant and was mainly mediated by a survived event. Overall, bystander CPR was indirectly associated with an $8.0 \%(\beta=0.080,95 \%$ confidence interval $[C I]=0.064-0.095, \quad P=0.002)$ increase in the possibility of survival rate (Table 4 , total indirect effect). The total indirect effect of bystander CPR on the survival rate through a survived event was $6.6 \%$ $(\beta=0.066,95 \% C I=0.051-0.081, P=0.002$; Table 4 , indirect effect), which accounted for $82.5 \%$ (0.066 of 0.080 ) of the total indirect effect.
A survived event has a significant impact on survival after OHCA. With every $1 \%$ increase in the survived event, the possibility of the survival rate will directly increase by $53.5 \%(\beta=0.535,95 \% C I=0.512-0.554$, $P=0.003$; Table 4). As shown in Fig. 3, although initial shockable rhythm and any ROSC were also positively related to the survival rate, they directly increased the chance of survival by only $6.7 \%$ and $3.1 \%$, respectively; their indirect effect on the survival rate through a survived event, however, was $6.4 \%$ and $5.6 \%$, respectively. Both the effect of initial shockable rhythm and any ROSC on the survival rate were mediated by a survived event, with every $1 \%$ increase in the rates of initial shockable rhythm and any ROSC directly leading to an $11.9 \%$ and $10.4 \%$ increase in the possibility of a survived event, respectively (Fig. 3).

When analyzing the relationships between bystander CPR, initial shockable rhythm, any ROSC, survived event, and survival rate, we found that bystander CPR affected the survival rate mainly through the "Bystander CPR-Survived Event-Survival to Discharge" path (P2, Table 4). The total indirect effect of bystander CPR on the survival rate through this path was $5.1 \%(\beta=0.051,95 \%$ $C I=0.036-0.066, P=0.002$ ).

The result of the multivariate path analysis among those patients that EMS attempted to resuscitate is displayed in Fig. 4 (model 2) and Table 5. This tested model also had a proper fit. The pathways and relationships among bystander CPR, initial shockable rhythm, any ROSC, survived event, and survival rate in those patients that EMS attempted to resuscitate were consistent with the results in all OHCA patients.

The sensitivity analyses are displayed in the Figs. S3S7 (models 3-7). The sensitivity analyses showed that the 
Table 3 Comparisons in characteristics between patients who survived to discharge and those who did not

\begin{tabular}{|c|c|c|c|c|c|c|}
\hline \multirow[t]{2}{*}{ Characteristics } & \multicolumn{3}{|l|}{ All patients $(\mathrm{N}=5014)^{\text {\& }}$} & \multicolumn{3}{|c|}{ EMS attempted resuscitation $(\mathrm{N}=2250)^{\text {\& }}$} \\
\hline & $\begin{array}{l}\text { Survival to Discharge } \\
(n=31)\end{array}$ & $\begin{array}{l}\text { Non-survival } \\
(n=4983)\end{array}$ & $P$ & $\begin{array}{l}\text { Survival to Discharge } \\
(n=31)\end{array}$ & $\begin{array}{l}\text { Non-survival } \\
(\mathrm{n}=2219)\end{array}$ & $P$ \\
\hline Age, median (IQR) & $63(52-73)$ & $78(63-85)$ & $<0.001$ & $63(52-73)$ & $70(57-80)$ & 0.021 \\
\hline Gender & & & 0.898 & & & 0.331 \\
\hline Male & $19(61.3)$ & $2998(60.2)$ & & $19(61.3)$ & $1540(69.4)$ & \\
\hline Female & $12(38.7)$ & 1985 (39.8) & & $12(38.7)$ & $679(30.6)$ & \\
\hline Arrest location & & & $<0.001$ & & & 0.018 \\
\hline At home & $18(58.1)$ & $4286(86.0)$ & & $18(58.1)$ & $1694(76.3)$ & \\
\hline At public place & $13(41.9)$ & $697(14.0)$ & & $13(41.9)$ & $525(23.7)$ & \\
\hline Witnessed status & & & $<0.001$ & & & 0.079 \\
\hline Non-witnessed & $7(22.6)$ & $2826(56.7)$ & & $7(22.6)$ & $843(38.0)$ & \\
\hline Witnessed & $24(77.4)$ & $2155(43.3))$ & & $24(77.4)$ & $1376(62.0)$ & \\
\hline Bystander CPR & & & $<0.001$ & & & 0.005 \\
\hline Yes & $12(38.7)$ & $469(9.4)$ & & $12(38.7)$ & $417(18.8)$ & \\
\hline No & $19(61.3)$ & $4514(90.6)$ & & $19(61.3)$ & $1802(81.2)$ & \\
\hline Bystanders trained in CPR & & & $<0.001$ & & & $<0.001$ \\
\hline Yes & $12(38.7)$ & $450(9.0)$ & & $12(38.7)$ & $300(13.5)$ & \\
\hline No & $19(61.3)$ & $4533(91.0)$ & & $19(61.3)$ & 1919 (86.5) & \\
\hline First monitored shockable rhythm & & & $<0.001$ & & & $<0.001$ \\
\hline Yes & $11(35.5)$ & $145(2.9)$ & & $11(35.5)$ & $132(5.9)$ & \\
\hline No & $20(64.5)$ & $4838(97.1)$ & & $20(64.5)$ & $2087(94.1)$ & \\
\hline Etiology & & & 0.445 & & & 0.279 \\
\hline Cardiac & $26(83.9)$ & $4400(88.3)$ & & $26(83.9)$ & $1993(89.8)$ & \\
\hline Non-cardiac & $5(16.1)$ & $583(11.7)$ & & $5(16.1)$ & $226(10.2)$ & \\
\hline Previous CVD & & & 0.022 & & & 0.036 \\
\hline Yes & $14(45.2)$ & $3235(64.9)$ & & $14(45.2)$ & $1407(63.4)$ & \\
\hline No & $17(54.8)$ & $1748(35.1)$ & & $17(54.8)$ & $812(36.6)$ & \\
\hline Response time (min), median (IQR) & $14(10-19)$ & $15(12-20)$ & 0.286 & $14(10-19)$ & $15(11-19)$ & 0.619 \\
\hline Any ROSC & & & $<0.001$ & & & $<0.001$ \\
\hline Yes & $6(19.4)$ & $84(1.7)$ & & $6(19.4)$ & $75(3.4)$ & \\
\hline No & 25 (80.6) & $4898(98.3)$ & & 25 (80.6) & 2144 (96.6) & \\
\hline Survived event & & & $<0.001$ & & & $<0.001$ \\
\hline Yes & $30(96.8)$ & $65(1.3)$ & & $30(96.8)$ & $62(2.8)$ & \\
\hline No & $1(3.2)$ & 4918 (98.7) & & $1(3.2)$ & $2157(97.2)$ & \\
\hline Survived to admission & & & $<0.001$ & & & $<0.001$ \\
\hline Yes & $31(100.0)$ & $19(0.4)$ & & $31(100.0)$ & $19(0.9)$ & \\
\hline No & 0 & $4964(99.6)$ & & 0 & $2200(99.1)$ & \\
\hline
\end{tabular}

Data are shown as frequency (percentage) or median (interquartile range). CPR, cardiopulmonary resuscitation; CVD, cardiovascular disease; IQR, interquartile range; ROSC, return of spontaneous circulation. ${ }^{\&}$ Excluding 28 patients who were lost to follow-up

indirect effect of bystander CPR on survival rate through increasing the survived event rate remained unchanged.

\section{Discussions}

To the best of our knowledge, this study was the first large prospective study that examined the trend of OHCA survival rate, survived event, and bystander CPR in China over the study period, and the possible causal relationship between bystander CPR, other pre-hospital factors and survival rates after OHCA. We found that the effect of bystander CPR on increasing the OHCA survival rate was mainly mediated by a survived event. Although the rate of bystander CPR increased from 2012 to 2015 in Beijing, the survival rate after OHCA was extremely low and had not improved over the same period possibly due to the fact that the rate of survived event has not increased during this period. 


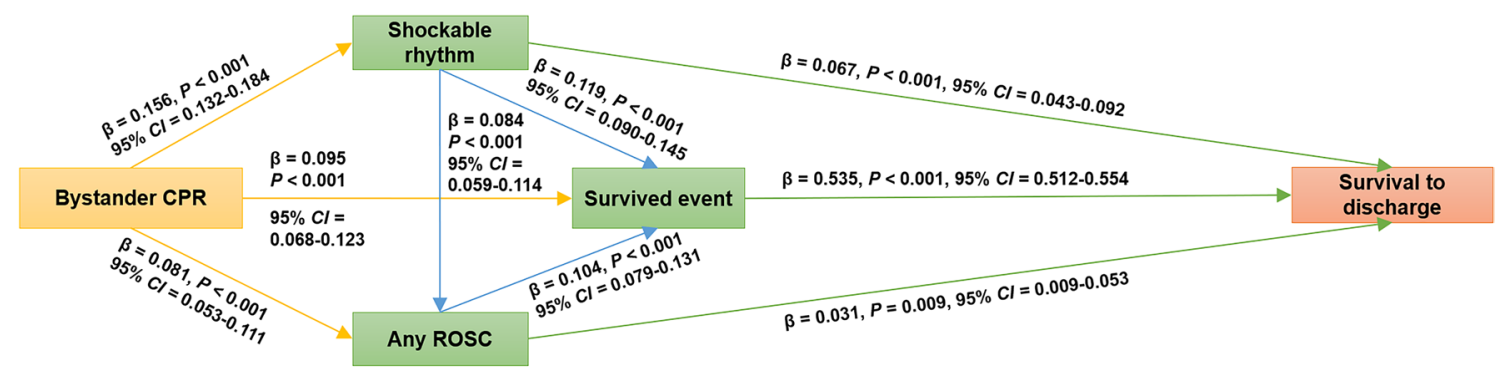

Model fit index: chi-square=0.019, $\mathrm{df}=1, P=0.998, \mathrm{GFI}=1.000, \mathrm{AGFI}=0.998, \mathrm{RMSEA}<0.001, \mathrm{CFI}=1.000$, Standardized RMR $=0.004, \mathrm{RFI}=1.000, \mathrm{NFI}=1.000$

Fig. 3 Multivariate path analysis model 1 (among all OHCA patients). $\mathrm{N}=5014$, excluding 28 patients who lost to follow-up. OHCA, Out-of-Hospital Cardiac Arrest; ROSC, return of spontaneous circulation; CPR, cardiopulmonary resuscitation; GFI, goodness-of-fit index; AGFl, adjusted goodness-of-fit index; RMSEA, root mean square error of approximation; CFI, comparative fit index; Standardized RMR, standardized root mean squared residual; RFI, relative fit index; $\mathrm{NFI}$, normed fit index; Cl, confidence interval; $\beta$, standardized estimate

Table 4 The direct effect, indirect effect, and total effect of bystander CPR on the survival after OHCA among all patients ( $N=5014)$ \&

\begin{tabular}{|c|c|c|c|c|c|}
\hline & \multirow[t]{2}{*}{$\begin{array}{l}\text { Unstandardized } \\
\text { Estimate }\end{array}$} & \multirow[t]{2}{*}{$\begin{array}{l}\text { Standardized } \\
\text { Estimate }\end{array}$} & \multicolumn{3}{|c|}{$\begin{array}{l}\text { Bootstrap Bias- } \\
\text { corrected } 95 \% \\
\text { confidence interval }\end{array}$} \\
\hline & & & Lower & Upper & $P$-value \\
\hline \multicolumn{6}{|l|}{ Multivariate Path Analyses Model of Bystander CPR on OHCA Survival } \\
\hline Bystander CPR-Initial Shockable Rhythm & 0.092 & 0.156 & 0.132 & 0.184 & 0.001 \\
\hline Bystander CPR-Survived Event & 0.044 & 0.095 & 0.068 & 0.123 & 0.002 \\
\hline Bystander CPR-ROSC & 0.036 & 0.081 & 0.053 & 0.111 & 0.002 \\
\hline Initial Shockable Rhythm-ROSC & 0.064 & 0.084 & 0.059 & 0.114 & 0.001 \\
\hline Initial Shockable Rhythm-Survived Event & 0.093 & 0.119 & 0.09 & 0.145 & 0.002 \\
\hline ROSC-Survival Event & 0.107 & 0.104 & 0.079 & 0.131 & 0.002 \\
\hline Initial Shockable Rhythm-Survival to Discharge & 0.030 & 0.067 & 0.043 & 0.092 & 0.002 \\
\hline Survived Event-Survival to Discharge & 0.308 & 0.535 & 0.512 & 0.554 & 0.003 \\
\hline ROSC-Survival to Discharge & 0.018 & 0.031 & 0.009 & 0.053 & 0.007 \\
\hline \multicolumn{6}{|l|}{ Effect of Bystander CPR on OHCA Survival } \\
\hline Total effect & 0.021 & 0.080 & 0.064 & 0.095 & 0.002 \\
\hline Total direct effect & 0.000 & 0.000 & 0.000 & 0.000 & 0.000 \\
\hline Total indirect effect & 0.021 & 0.080 & 0.064 & 0.095 & 0.002 \\
\hline \multicolumn{6}{|l|}{ Mediation Analyses and Potential Paths } \\
\hline $\mathrm{P}_{1}$ : Bystander CPR-Initial Shockable Rhythm-Survival to Discharge & 0.003 & 0.010 & 0.007 & 0.015 & 0.002 \\
\hline $\mathrm{P}_{2}$ : Bystander CPR-Survived Event-Survival to Discharge & 0.014 & 0.051 & 0.036 & 0.066 & 0.002 \\
\hline $\mathrm{P}_{3}:$ Bystander CPR-ROSC-Survival to Discharge & 0.001 & 0.003 & 0.001 & 0.005 & 0.006 \\
\hline $\mathrm{P}_{4}$ : Bystander CPR-Initial Shockable Rhythm-ROSC-Survival to Discharge & 0.000 & 0.000 & 0.000 & 0.001 & 0.004 \\
\hline $\begin{array}{l}\text { P }_{5} \text { : Bystander CPR-Initial Shockable Rhythm-ROSC-Survived Event-Survival to Dis- } \\
\text { charge }\end{array}$ & 0.000 & 0.001 & 0.000 & 0.001 & 0.001 \\
\hline$P_{6}$ : Bystander CPR-Initial Shockable Rhythm-Survived Event-Survival to Discharge & 0.003 & 0.010 & 0.007 & 0.013 & 0.001 \\
\hline $\mathrm{P}_{7}$ : Bystander CPR-ROSC-Survived Event-Survival to Discharge & 0.001 & 0.004 & 0.003 & 0.007 & 0.002 \\
\hline \multicolumn{6}{|l|}{ The Total Indirect Effect of Bystander CPR on OHCA Survival through Survived Event } \\
\hline Mediator: Survived Event $\left(P_{2}+P_{5}+P_{6}+P_{7}\right)$ & 0.018 & 0.066 & 0.051 & 0.081 & 0.002 \\
\hline
\end{tabular}

Bystander CPR: bystander cardiopulmonary resuscitation. ROSC: return of spontaneous circulation. OHCA, out-of-hospital cardiac arrest. P: path. ${ }^{\circledR}$ Excluding 28 patients who lost to follow-up

Our findings confirm the hypothesis that the effect of bystander CPR on increasing OHCA survival rate is mainly mediated by increased survived event rate; only increasing the rates of shockable rhythm or any ROSC without increasing survived event rate had very limited effect on the survival rates for patients with OHCA. 


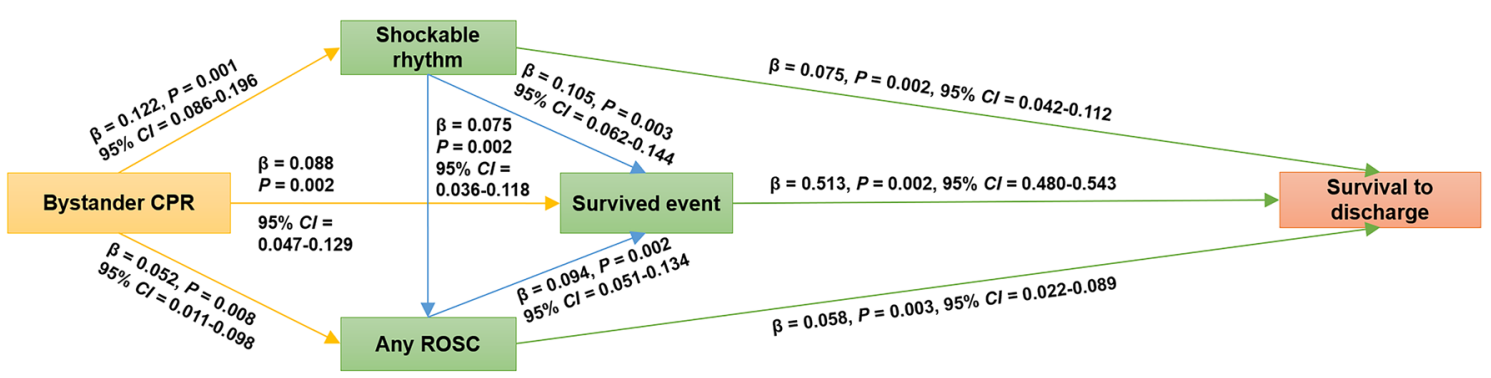

Model fit index: chi-square=0.322, $\mathrm{df}=1, P=0.571, \mathrm{GFI}=1.000, \mathrm{AGFI}=0.999, \mathrm{RMSEA}<0.001, \mathrm{CFI}=1.000$, Standardized RMR $=0.026, \mathrm{RFI}=0.996, \mathrm{NFI}=1.000$

Fig. 4 Multivariate path analysis model 2 (among patients that EMS attempted to resuscitate). N=2250, excluding 28 patients lost-to-follow-up. EMS, Emergency Medical Services; OHCA, Out-of-Hospital Cardiac Arrest; ROSC, return of spontaneous circulation; CPR, cardiopulmonary resuscitation; GFI, goodness-of-fit index; AGFI, adjusted goodness-of-fit index; RMSEA, root mean square error of approximation; $\mathrm{CFI}$, comparative fit index; Standardized RMR, standardized root mean squared residual; RFI, relative fit index; NFI, normed fit index; Cl, confidence interval; $\beta$, standardized estimate

Table 5 The direct effect, indirect effect, and total effect of bystander CPR on the survival after OHCA among patients that EMS attempted to resuscitate $(N=2250)^{\&}$

Unstandardized Standardized Bootstrap Bias-

Estimate Estimate

corrected $95 \%$

confidence interval

Lower Upper $P$-value

Multivariate Path Analyses Model of Bystander CPR on OHCA Survival

Bystander CPR-Initial Shockable Rhythm

0.076

Bystander CPR-Survived Event

Bystander CPR-ROSC

Initial Shockable Rhythm-ROSC

Initial Shockable Rhythm-Survived Event

Initial Shockable Rhythm-Survival to Discharge

Survived Event-Survival to Discharge

ROSC-Survival to Discharge

Effect of Bystander CPR on OHCA Survival

Total effect

Total direct effect

Total indirect effect

Mediation Analyses and Potential Paths

$P_{1}$ : Bystander CPR-Initial Shockable Rhythm-Survival to Discharge

$\mathrm{P}_{2}$ : Bystander CPR-Survived Event-Survival to Discharge

$P_{3}$ : Bystander CPR-ROSC-Survival to Discharge

$\mathrm{P}_{4}$ : Bystander CPR-Initial Shockable Rhythm-ROSC-Survival to Discharge

$P_{5}$ : Bystander CPR-Initial Shockable Rhythm-ROSC-Survived Event-Survival to Discharge

$\mathrm{P}_{6}$ : Bystander CPR-Initial Shockable Rhythm-Survived Event-Survival to Discharge

$P_{7}$ : Bystander CPR-ROSC-Survived Event-Survival to Discharge

The Total Indirect Effect of Bystander CPR on OHCA Survival through Survived Event

Mediator: Survived Event $\left(P_{2}+P_{5}+P_{6}+P_{7}\right)$
ROSC-Survival Event
0.045

0.024

0.055

0.085

0.103

0.034

0.290

0.036

0.019

0.000

0.019

0.003

0.013

0.001

0.000

0.000

0.002

0.001

0.016

\subsection{2}

0.088

0.052

0.075

0.105

0.094

0.075

0.513

0.058

0.086

0.047

0.011

0.036

0.062

0.051

0.112

$0.480 \quad 0.543$

$0.022 \quad 0.089 \quad 0.003$

Bystander CPR: bystander cardiopulmonary resuscitation. ROSC: return of spontaneous circulation. OHCA, out-of-hospital cardiac arrest. P: path. ${ }^{\circledR}$ Excluding 28 patients lost-to-follow-up 
However, given that shockable rhythm and ROSC were positively associated with the survival rate after OHCA $[9,14,19,20]$, most studies did not focus on survived event rate, but rather focused on whether increasing bystander CPR could increase the likelihood of shockable rhythm and ROSC [20,30].

Takahashi and colleagues [30] found that an increased bystander CPR rate was significantly associated with an increased shockable rhythm rate, ROSC rate, and improved survival rates. Takahashi's findings support the findings in developed countries [9-11], but they do not explain the results in Japan and Australia [12, 13], where the survived event rate did not improve over time and the survival rate did not increase either [13], or only increased by $0.8 \%$ [12]. In our study, the results of multivariate path analysis suggested that whether bystander CPR can increase the OHCA survival rate depends largely on the presence of a survived event, a term which has been mentioned in the Utstein Resuscitation Registry Templates for OHCA since 2004 [15, 31], but has rarely been reported as a predicting factor of OHCA survival rate in most of the current published studies [9, 14, 32].

It is well known in general that patients who had initial shockable rhythm - no matter with or without bystander CPR - had higher proportions of favorable outcomes $[23,28]$. The path analysis of our study suggests that initial shockable rhythm was positively associated with increased survival rate, which was consistent with previous studies [23, 28]. Moreover, our study highlights the role of survived event in increasing the survival rate after OHCA. Our study found that for patients with initial shockable rhythm, the chance of survival increased by only $6.7 \%$ if the patients had not survive the event; the possibility of a survival rate could increase to $11.9 \%$ if the patients survived the event. In line with previous reports $[6,22]$, we also indicated that ROSC was associated with an improved survival rate. Of note, our study suggested that despite patients having achieved any ROSC after defibrillation, the possibility of survival rate increased by only $3.1 \%$ if the patient did not survive the event; however, the possibility of a survival rate could increase to $10.4 \%$ if the patients survived the event.

The reasons for our findings are obvious. Cardiac arrest is a disorder characterized by cessation of the pumping function of the heart, which usually causes death if the heart does not achieve ROSC within minutes and sustain ROSC at the emergency department (that is, survived event) [33]. The sinoatrial node is the primary cardiac pacemaker with the highest automaticity of heart [34]. The sinoatrial node cells may suffer from cardiac ischemia when patients do not survive the event after OHCA [35]. The cardiac ischemia may lead to a reduced automaticity in the sinoatrial node cells, and result in decreased energy supply for supporting the contractility of the cardiac myocytes [35]. The survived event after OHCA depends largely on whether the sinoatrial node cells return automaticity and contractility within the timeframe of cardiac ischemia [36, 37]. One study found that bystander CPR may help the cardiac myocytes to recover automaticity and contractility, and improve the possibility of the rate of survived event [38]. Thus, after receiving bystander CPR or defibrillation, if the patient could achieve ROSC quickly and survived the event, the sinoatrial node cells could return automaticity and contractility in time, and thereby the chance of survival for patients with OHCA could increase [37]. To increase the survival rate after OHCA in China, more focus on the quality of bystander CPR and the chance of a survived event are urgently needed [39].

\section{Limitations}

This study has several limitations. First, as only 31 patients survived to discharge, this study may not have the power to explore the effect of the study factors on survival rates. The overall survival rates, however, were still very low (1.2\%) even if those patients who were lostto-follow-up were considered as survivals to discharge. To further verify our findings and to explore the effect of each factor on survival rates, a large-scale study is needed that includes more patients who survived to discharge. Second, this study was not a nationwide OHCA registry prospective study, which may hinder the generalizability of our findings. However, controlling for the inclusion bias, we consecutively screened OHCA patients from the official EMS in Beijing which has the largest number of emergency patients transferred. Third, AED was not available in public areas in Beijing; therefore, bystander defibrillation was not provided during the study period, which might reduce the effect of initial shockable rhythm on OHCA survival. Moreover, in this study, we can not test the effect of early defibrillation on increasing the survival rate. More studies exploring the pathways among early defibrillation, bystander CPR, other predictors of OHCA survival (ROSC, initial shockable rhythm, survived event), and survival rate are warranted. Finally, we did not collect data from February to June in 2011 and from November to December in 2016, which might bias the results of the study.

\section{Conclusions}

The rate of survival after OHCA was still extremely low in Beijing, and did not improve from 2012 to 2015. The effect of bystander CPR in increasing survival rates of OHCA was mainly mediated by a survived event. This suggests that efforts, such as facilitating high-quality CPR training to increase the rate of survived event, will have a substantial 
effect on improving the survival rate after OHCA in Beijing.

\begin{abstract}
Abbreviations
ACLS: Advanced cardiac life support; AEDs: Automated external defibrillators; Cl: Confidence interval; CPR: Cardiopulmonary resuscitation; CVD: Cardiovascular disease; EMS: Emergency Medical Service; IQR: Interquartile range; OHCA: Out-of-hospital cardiac arrest; ROSC: Return of spontaneous circulation.
\end{abstract}

\section{Supplementary Information}

The online version contains supplementary material available at https://doi. org/10.1186/s12872-021-02446-z.

\section{Additional file 1. Supplemental Figure 1. The map of Emergency} Medical Services centers in Beijing. Supplemental Figure 2. Survival rates of out-of-hospital cardiac arrest among bystanders with previous CPR training. Supplemental Figure 3. Sensitivity analyses: multivariate path analysis model 3. Supplemental Figure 4. Sensitivity analyses: multivariate path analysis model 4. Supplemental Figure 5. Sensitivity analyses: multivariate path analysis model 5. Supplemental Figure 6. Sensitivity analyses: multivariate path analysis model 6. Supplemental Figure 7. Sensitivity analyses: multivariate path analysis model 7. Supplemental Table 1. Comparisons in characteristics between patients who survived to discharge and those who did not.

\section{Acknowledgements}

The authors would like to thank all the colleagues from the Beijing Emergency Medical Centre, all the practitioners who collected medical information from the patients included in this study, and all study participants. Special thanks go to Karen V. Lamb, who is a Visiting Associate Clinical Professor from the University of Illinois Chicago College of Nursing Associate, a Professor Emerita at Rush, and a Visiting Professor at Capital Medical University, for her review of the manuscript. We also thank Professor Dianxu Ren from Pittsburgh University for his helpful advice on data analysis.

\section{Authors' contributions}

YW designed the trial, obtained funding for the trial, and provided critical revisions of the manuscript. YC and PY drafted the manuscript and conducted data analysis. PY, JL, YL, DG, JL, and PH collected data. All authors read and approved the final manuscript.

\section{Funding}

This work was supported by the Funding Project for Academic Human Resources Development in Institutions of Higher Learning under the Jurisdiction of Beijing Municipality (Grant Number \#PHR 201107114, Principal Investigator: YW). The funding body played no role in the design of the study and collection, analysis, and interpretation of data and in writing the manuscript.

\section{Declarations}

\section{Ethics approval and consent to participate}

This study was approved by the Institutional Review Board of the Capital Medical University (No. 2010SY26). Informed consent from participants was waived by the Institutional Review Board of the Capital Medical University.

\section{Consent for publication}

Not applicable.

\section{Availability of data and materials}

The datasets used or analysed during the current study are available from the corresponding author on reasonable request.

\section{Competing interests}

The authors report no conflict of interest.

\section{Author details}

${ }^{1}$ School of Nursing, Capital Medical University, No. 10, You An Men Wai Xi Tou Tiao, Fengtai District, Beijing 100069, China. ${ }^{2}$ Beijing Emergency Medical Center, No. 103, Qian Men Xi Da Jie, Xicheng District, Beijing 100031, China.

Received: 10 June 2021 Accepted: 24 December 2021

Published online: 31 December 2021

\section{References}

1. Yan S, Gan Y, Jiang N, Wang R, Chen Y, Luo Z, et al. The global survival rate among adult out-of-hospital cardiac arrest patients who received cardiopulmonary resuscitation: a systematic review and meta-analysis. Crit Care 2020;24(1):61. https://doi.org/10.1186/s13054-020-2773-2.

2. Zhang S. Sudden cardiac death in China: current status and future perspectives. Europace. 2015;17(Suppl 2):14-8. https://doi.org/10.1093/ europace/euv143.

3. Beard JR, Officer AM, Cassels AK. The World Report on Ageing and Health. Gerontologist. 2016;56(Suppl 2):S163-166. https://doi.org/10.1093/ geront/gnw037.

4. Sun $\mathrm{R}$, $\mathrm{Cao} \mathrm{H}$, Zhu X, Liu J-P, Dong E. Current aging research in China. Protein Cell. 2015;6(5):314-21. https://doi.org/10.1007/s13238-015-0145-5.

5. Song J, Guo W, Lu X, Kang X, Song Y, Gong D. The effect of bystander cardiopulmonary resuscitation on the survival of out-of-hospital cardiac arrests: a systematic review and meta-analysis. Scand J Trauma Resusc Emerg Med. 2018;26(1):86. https://doi.org/10.1186/s13049-018-0552-8.

6. Sasson C, Rogers MA, Dahl J, Kellermann AL. Predictors of survival from out-of-hospital cardiac arrest: a systematic review and meta-analysis. Circ Cardiovasc Qual Outcomes. 2010;3(1):63-81. https://doi.org/10.1161/ circoutcomes.109.889576.

7. Field JM, Hazinski MF, Sayre MR, Chameides L, Schexnayder SM, Hemphill R, et al. Part 1: executive summary: 2010 American Heart Association Guidelines for Cardiopulmonary Resuscitation and Emergency Cardiovascular Care. Circulation. 2010;122(18 Suppl 3):S640-656. https://doi.org/10. 1161/circulationaha.110.970889.

8. Cummins RO, Ornato JP, Thies WH, Pepe PE. Improving survival from sudden cardiac arrest: the "chain of survival" concept. A statement for health professionals from the Advanced Cardiac Life Support Subcommittee and the Emergency Cardiac Care Committee, American Heart Association. Circulation. 1991;83(5):1832-47. https://doi.org/10.1161/01.cir.83.5. 1832

9. Grunau B, Kawano T, Dick W, Straight R, Connolly H, Schlamp R, et al. Trends in care processes and survival following prehospital resuscitation improvement initiatives for out-of-hospital cardiac arrest in British Columbia, 2006-2016. Resuscitation. 2018;125:118-25. https://doi.org/10.1016/j. resuscitation.2018.01.049

10. Blom MT, Beesems SG, Homma PC, Zijlstra JA, Hulleman M, van Hoeijen DA, et al. Improved survival after out-of-hospital cardiac arrest and use of automated external defibrillators. Circulation. 2014;130(21):1868-75. https://doi.org/10.1161/circulationaha.114.010905.

11. Chan PS, McNally B, Tang F, Kellermann A. Recent trends in survival from out-of-hospital cardiac arrest in the United States. Circulation. 2014;130(21):1876-82. https://doi.org/10.1161/circulationaha.114.009711.

12. Kitamura T, Iwami T, Kawamura T, Nitta M, Nagao K, Nonogi H, et al. Nationwide improvements in survival from out-of-hospital cardiac arrest in Japan. Circulation. 2012;126(24):2834-43. https://doi.org/10.1161/circu lationaha.112.109496.

13. Lim SL, Smith K, Dyson K, Chan SP, Earnest A, Nair R, et al. Incidence and Outcomes of Out-of-Hospital Cardiac Arrest in Singapore and Victoria: A Collaborative Study. J Am Heart Assoc. 2020;9(21):e015981. https://doi. org/10.1161/JAHA.119.015981.

14. Buick JE, Drennan IR, Scales DC, Brooks SC, Byers A, Cheskes S, et al. Improving temporal trends in survival and neurological outcomes after out-of-hospital cardiac arrest. Circulation Circ Cardiovasc Qual Outcomes. 2018;11(1):e003561. https://doi.org/10.1161/circoutcomes.117.003561.

15. Perkins GD, Jacobs IG, Nadkarni VM, Berg RA, Bhanji F, Biarent D, et al. Cardiac arrest and cardiopulmonary resuscitation outcome reports: update of the Utstein Resuscitation Registry Templates for Out-of-Hospital Cardiac Arrest: a statement for healthcare professionals from a task force of the International Liaison Committee on Resuscitation (American Heart 
Association, European Resuscitation Council, Australian and New Zealand Council on Resuscitation, Heart and Stroke Foundation of Canada, InterAmerican Heart Foundation, Resuscitation Council of Southern Africa, Resuscitation Council of Asia); and the American Heart Association Emergency Cardiovascular Care Committee and the Council on Cardiopulmonary, Critical Care, Perioperative and Resuscitation. Circulation. 2015;132(13):1286-300. https://doi.org/10.1161/cir.0000000000000144.

16. Huang JB, Lee KH, Ho YN, Tsai MT, Wu WT, Cheng FJ. Association between prehospital prognostic factors on out-of-hospital cardiac arrest in different age groups. BMC Emerg Med. 2021;21(1):3. https://doi.org/10.1186/ s12873-020-00400-4.

17. Shao F, Li CS, Liang LR, Li D, Ma SK. Outcome of out-of-hospital cardiac arrests in Beijing, China. Resuscitation. 2014;85(11):1411-7. https://doi. org/10.1016/j.resuscitation.2014.08.008.

18. Wissenberg M, Lippert FK, Folke F, Weeke P, Hansen CM, Christensen EF, et al. Association of national initiatives to improve cardiac arrest management with rates of bystander intervention and patient survival after outof-hospital cardiac arrest. JAMA. 2013;310(13):1377-84. https://doi.org/10. 1001/jama.2013.278483.

19. Tanguay-Rioux X, Grunau B, Neumar R, Tallon J, Boone R, Christenson J. Is initial rhythm in OHCA a predictor of preceding no flow time? Implications for bystander response and ECPR candidacy evaluation. Resuscitation. 2018;128:88-92. https://doi.org/10.1016/j.resuscitation.2018.05.002.

20. Fukuda T, Ohashi-Fukuda N, Hayashida K, Kukita I. Association of bystander cardiopulmonary resuscitation and neurological outcome after out-of-hospital cardiac arrest due to drowning in Japan, 2013-2016. Resuscitation. 2019;141:111-20. https://doi.org/10.1016/j.resuscitation. 2019.06.005.

21. Franek O, Pokorna M, Sukupova P. Pre-hospital cardiac arrest in Prague, Czech Republic-the Utstein-style report. Resuscitation. 2010;81(7):831-5. https://doi.org/10.1016/j.resuscitation.2010.03.005.

22. Lee SY, Hong KJ, Shin SD, Ro YS, Song KJ, Park JH, et al. The effect of dispatcher-assisted cardiopulmonary resuscitation on early defibrillation and return of spontaneous circulation with survival. Resuscitation. 2019;135:21-9. https://doi.org/10.1016/.j.resuscitation.2019.01.004.

23. Matsuyama T, Kitamura T, Kiyohara K, Kiguchi T, Kobayashi D, Nishiyama C, et al. Assessment of the 11-year nationwide trend of out-of-hospital cardiac arrest cases among elderly patients in Japan (2005-2015). Resuscitation. 2018;131:83-90. https://doi.org/10.1016/j.resuscitation.2018.08. 011.

24. Von Elm E, Altman DG, Egger M, Pocock SJ, Gøtzsche PC, Vandenbroucke JP. The Strengthening the Reporting of Observational Studies in Epidemiology (STROBE) statement: guidelines for reporting observational studies. Ann Intern Med. 2007;147(8):573-7. https://doi.org/10.7326/0003-4819147-8-200710160-00010.

25. National Bureau of Statistics of China. http://data.stats.gov.cn/index.htm. 2016.

26. Neumar RW, Otto CW, Link MS, Kronick SL, Shuster M, Callaway CW, et al. Part 8: adult advanced cardiovascular life support: 2010 American Heart Association Guidelines for Cardiopulmonary Resuscitation and Emergency Cardiovascular Care. Circulation. 2010;122(18 Suppl 3):S729-767. https://doi.org/10.1161/circulationaha.110.970988.

27. Hunyadi-Anticevic S, Colak Z, Funtak IL, Lukic A, Filipovic-Grcic B, Tomljanovic $B$, et al. European Resuscitation Council guidelines for resuscitation 2010. Lijec Vjesn. 2011;133(1-2):1-14.

28. Kleinman ME, Brennan EE, Goldberger ZD, Swor RA, Terry M, Bobrow BJ, et al. Part 5: Adult Basic Life Support and Cardiopulmonary Resuscitation Quality: 2015 American Heart Association Guidelines Update for Cardiopulmonary Resuscitation and Emergency Cardiovascular Care. Circulation. 2015;132(18 Suppl 2):S414-435. https://doi.org/10.1161/cir. 00000000000000259 .

29. Hu Lt, Bentler PM. Cutoff criteria for fit indexes in covariance structure analysis: conventional criteria versus new alternatives. Struct Equ Model. 1999;6(1):1-55.

30. Takahashi H, Sagisaka R, Natsume Y, Tanaka S, Takyu H, Tanaka H. Does dispatcher-assisted CPR generate the same outcomes as spontaneously delivered bystander CPR in Japan? Am J Emerg Med. 2018;36(3):384-91. https://doi.org/10.1016/j.ajem.2017.08.034.

31. Jacobs I, Nadkarni V, Bahr J, Berg RA, Billi JE, Bossaert L, et al. Cardiac arrest and cardiopulmonary resuscitation outcome reports: update and simplification of the Utstein templates for resuscitation registries: a statement for healthcare professionals from a task force of the International Liaison Committee on Resuscitation (American Heart Association, European Resuscitation Council, Australian Resuscitation Council, New Zealand Resuscitation Council, Heart and Stroke Foundation of Canada, InterAmerican Heart Foundation, Resuscitation Councils of Southern Africa). Circulation. 2004;1 10(21):3385-97. https://doi.org/10.1161/01.Cir.00001 47236.85306 .15$.

32. Okubo M, Atkinson EJ, Hess EP, White RD. Improving trend in ventricular fibrillation/pulseless ventricular tachycardia out-of-hospital cardiac arrest in Rochester, Minnesota: A 26-year observational study from 1991 to 2016. Resuscitation. 2017;120:31-7. https://doi.org/10.1016/j.resuscitat ion.2017.08.014.

33. Recommended guidelines for uniform reporting of data from out-ofhospital cardiac arrest (new abridged version). The "Utstein style". The European Resuscitation Council, American Heart Association, Heart and Stroke Foundation of Canada, and Australian Resuscitation Council. Bt Heart J. 1992; 67(4):325-333. https://doi.org/10.1136/hrt.67.4.325

34. Aziz Q, Li Y, Tinker A. Potassium channels in the sinoatrial node and their role in heart rate control. Channels. 2018;12(1):356-66. https://doi.org/10. 1080/19336950.2018.1532255.

35. Bai X, Wang K, Yuan Y, Li Q, Dobrzynski H, Boyett MR, et al. Mechanism underlying impaired cardiac pacemaking rhythm during ischemia: a simulation study. Chaos. 2017;27(9):093934. https://doi.org/10.1063/1. 5002664 .

36. Alexandre J, Beygui F, Puddu P-E, Manrique A, Rouet R, Milliez P. Electrophysiological and antiarrhythmic properties of potassium canrenoate during myocardial ischemia-reperfusion. J Cardiovasc Pharmacol Ther. 2015;20(3):313-21. https://doi.org/10.1177/1074248414557036.

37. Grunau B, Reynolds J, Scheuermeyer F, Stenstom R, Stub D, Pennington S, et al. Relationship between Time-to-ROSC and Survival in Out-of-hospital Cardiac Arrest ECPR Candidates: When is the Best Time to Consider Transport to Hospital? Prehosp Emerg Care. 2016;20(5):615-22. https://doi.org/ 10.3109/10903127.2016.1149652.

38. Kim H, Hwang SO, Lee CC, Lee KH, Kim JY, Yoo BS, et al. Direction of blood flow from the left ventricle during cardiopulmonary resuscitation in humans: its implications for mechanism of blood flow. Am Heart J. 2008;156(6):1222.e1221-1227. https://doi.org/10.1016/j.ahj.2008.09.003.

39. Duber HC, McNellan CR, Wollum A, Phillips B, Allen K, Brown JC, et al. Public knowledge of cardiovascular disease and response to acute cardiac events in three cities in China and India. Heart (British Cardiac Society). 2018;104(1):67-72. https://doi.org/10.1136/heartjnl-2017-311388.

\section{Publisher's Note}

Springer Nature remains neutral with regard to jurisdictional claims in published maps and institutional affiliations.

\footnotetext{
Ready to submit your research? Choose BMC and benefit from:

- fast, convenient online submission

- thorough peer review by experienced researchers in your field

- rapid publication on acceptance

- support for research data, including large and complex data types

- gold Open Access which fosters wider collaboration and increased citations

- maximum visibility for your research: over $100 \mathrm{M}$ website views per year
}

At BMC, research is always in progress.

Learn more biomedcentral.com/submissions 